\title{
Institutional Knowledge and its Normative Implications
}

\section{Hormio, Säde}

de Gruyter

2020

Hormio , S 2020 , Institutional Knowledge and its Normative Implications . in M Garcia-Godinez, R Mellin \& R Tuomela (eds), Social Ontology, Normativity and Law . de Gruyter , Berlin/Boston , pp. 63-78 . https://doi.org/10.1515/9783110663617-005

http://hdl.handle.net/10138/321477

https://doi.org/10.1515/9783110663617-005

submittedVersion

Downloaded from Helda, University of Helsinki institutional repository.

This is an electronic reprint of the original article.

This reprint may differ from the original in pagination and typographic detail.

Please cite the original version. 


\section{Institutional knowledge and its normative implications}

Säde Hormio (Practical Philosophy \& TINT, University of Helsinki)

\section{Preprint}

Forthcoming in García and Mellin (eds.) Social Ontology, Normativity and Law. De Gruyter, Berlin.

For over fifty years, the United States of America has known that carbon dioxide ("CO2") pollution from burning fossil fuels was causing global warming and dangerous climate change, and that continuing to burn fossil fuels would destabilize the climate system on which present and future generations of our nation depend for their wellbeing and survival. Defendants also knew the harmful impacts of their actions would significantly endanger Plaintiffs, with the damage persisting for millennia. Despite this knowledge, Defendants continued their policies and practices of allowing the exploitation of fossil fuels.

- First Amended Complaint for Declaratory and Injunctive Relief, Juliana v. U.S.

We attribute knowledge to institutions on a daily basis, saying things like "the government knew about the threat" or "the university did not act upon the knowledge it had about the harassment". Institutions can also attribute knowledge to themselves, like when Maybank Global Banking claims that it offers its customers "deep expertise and vast knowledge" of the Southeast Asia region, or when the United States Geological Survey states that it understands complex natural science phenomena like the probability of earthquakes occurring along a given fault line.

This article aims to discover when we can correctly attribute knowledge to an institution. I find this an interesting question, especially because when something does go wrong, all too often the official line of response from institutions is that they were unaware of the situation: in other words, they did not have enough information at their disposal. I will argue that institutions have fewer excuses for being ignorant than individuals do, and that many admissions of institutional knowledge are too modest. I begin by discussing a real-life example of the latter, before turning my attention to the usually fragmented nature of institutional knowledge. I also discuss the robustness of this knowledge, offering a distinction between two types of institutional knowledge. I then discuss knowledge parameters and why institutions have fewer excuses for not knowing about something than individuals do. I round off the chapter by examining institutional knowledge on climate change. 
A clarificatory note is in order: by 'institutions' I refer throughout to large organisations, and not to the wider meaning of institutions as shared and established social practices and laws, although legal institutions are naturally included. Other examples of institutions include universities, governments, art establishments, and insurance companies. What these types of large organisations have in common is that they are established to be more or less permanent in nature. Hence, enterprises and other temporal organisations with short-term goals do not qualify as institutions.

\section{What did the USA know?}

In September 2015, a group of 21 young people and children brought a lawsuit against the United States of America. The First Amended Complaint for Declaratory and Injunctive Relief filed by Kelsey Cascadia Rose Juliana et al. (henceforth Juliana) argues that the state has acted indifferently in a deliberate way to the known peril of climate change, which they have been involved in creating. According to the plaintiffs, this infringes on their constitutional rights to life, liberty, and property. In addition, they argue that the state has also failed to protect land, water, air, and living things - the heritage of the whole nation.

Juliana is coordinated by Our Children's Trust, a non-profit organisation with several cases pending, and inspired by the Atmospheric Trust Litigation (ATL) approach, originated by Mary Christina Wood, Professor of Law at the University of Oregon. ${ }^{1}$ ATL draws on the public trust doctrine, which was first articulated in Roman law. At its heart lies the idea of designating government actors as trustees of essential natural capital, which is viewed as "an enduring ecological endowment". ${ }^{2}$ ATL applies public trust principles to the atmosphere and adopts a fundamental rights approach to climate change. ${ }^{3}$ The plaintiffs do not seek damages for themselves, but rather for the court to order the state to draw up a plan to phase out fossil fuels and reduce excess carbon in the atmosphere, and to monitor compliance with the same. ${ }^{4}$ Juliana et al. argue that the current actions of the state favour "the present, temporary

\footnotetext{
1 Wood 2013.

2 Blumm and Wood 2017: 22.

${ }^{3}$ Although the atmosphere has not traditionally been thought of as a natural resource in the public trust context, "air" is mentioned in the Institutes of Justinian, the Roman sixth-century recodification of an ancient law, and it has been affirmed as public property by the U.S. Supreme Court in an earlier decision (Rubinton 2017). The denial in 2016 of motions to dismiss in Juliana v. U.S. by U.S. District Court Judge Ann Aiken made history by asserting that a climate system capable of sustaining human life is a fundamental constitutional right.

${ }_{4}$ This is why it is unlikely that the case will go to trial: appellate courts are reluctant to allow district courts to tinker with standards set by the Environmental Protection Agency, holding that the juridical branch should not be setting its own standards. Regardless of what happens, the case has still opened up interesting avenues for future climate change litigation by linking climate change to the public trust doctrine.
} 
economic benefits of certain citizens, especially corporations" over those of the plaintiffs' constitutional rights.

The U.S. Department of Justice responded to the case on behalf of the federal defendants in January 2017, just before the Obama administration was leaving office, and admitted that current and projected greenhouse gas emissions "constitute a threat to public health and welfare". They also agreed with the plaintiffs that carbon emissions from the United States accounted for more than a quarter of cumulative global $\mathrm{CO}_{2}$ emissions from 1850 to 2012. What is more, they admitted that they had known about the issue for a long time:

Federal Defendants admit that for over fifty years some officials and persons employed by the federal government have been aware of a growing body of scientific research concerning the effects of fossil fuel emissions on atmospheric concentrations of $\mathrm{CO}_{2}-$ including that increased concentrations of atmospheric $\mathrm{CO}_{2}$ could cause measurable long-lasting changes to the global climate, resulting in an array of severe deleterious effects to human beings, which will worsen over time.

It is clear that the U.S. Department of Justice is not trying to question climate change science in their response. Rather, what they deny is the plaintiffs' claims that they have ignored expert warnings and have wilfully ignored the impending harm to future generations. ${ }^{5}$ The response also stated that the term "United States" is "vague" and "ambiguous" and that the "Federal Defendants cannot attribute knowledge to it". From the list of defendants, which includes both state departments and individuals in their official capacity representing various state branches, it is clear that what is at stake is the knowledge that the Federal Government possessed about the issue. What they contested in many places was having sufficient information or knowledge. While some of these relate to accusations that are perhaps too vague to obtain knowledge about in the sense required, I find the admission of knowledge too modest in the quote above.

Note how in the quote the admission is that "some officials and persons employed by the federal government have been aware [emphasis mine]" of the issue for many decades. For an institution to be said to have knowledge about an issue, not every member needs to have knowledge about it. It is not

\footnotetext{
5 At the same time, they admit that they "permit, authorize, and subsidize fossil fuel extraction, development, consumption, and exportation" while knowing that these activities produce $\mathrm{CO}_{2}$ emissions and increase the atmospheric concentration of $\mathrm{CO}_{2}$. They also acknowledge, as shown in the quote above, that this could result in many severe harmful effects for human beings, and is set to worsen over time. The apparent contradiction can be explained by what the costs and benefits of these activities are estimated to be, but I set that issue aside here.
} 
even necessary for the knowledge to be widely distributed within the institution, or for it to be readily available to interested members, or so I will argue below.

\section{Institutional knowledge}

Knowledge is not evenly distributed within institutions. It would be totally implausible to demand that for an institution to have knowledge about an issue, all of its members should duly have knowledge about it. It is economical for an institution to consist of groups of experts that can work together when needed, as this allows for a wide range of skills and expertise to be employed. In fact, the capacity for an institution to have broad and deep knowledge is based on their ability to pool together knowledge from various individuals and sources. Institutions requires specialisation to be able to have all the skills and knowledge they need, so fragmentation of knowledge is an inevitable consequence of this.

If we consider an educational institution like a university, it is composed of several specialised faculties and departments consisting of experts in a given field. ${ }^{6}$ Only a fraction of the knowledge found within the institution is acquired by the university's top management, or shared among the faculties (even given the inter-, multi- and transdisciplinary research that is in vogue with funders these days). This does not mean that the information cannot be accessed when necessary, for instance when a journalist or a government agency contacts the university to obtain information about the latest research on some issue.

In general, highly fragmented information within institutions is fine as long as groups of experts are willing to share their knowledge if and when needed. They should also share with others information that affects the institution as a whole, unless there is a policy by the upper levels of the institution to suppress this knowledge. ${ }^{7}$ For an institution to be said to have knowledge about something, not every member of it - or indeed even the majority - need to have knowledge about it. Nor does the availability of the information need to be widespread. It is enough that those who are working in areas requiring this knowledge possess it or, at least, that they could possess it if the executives so wished.

It is important to distinguish between when an institution has knowledge about something through its members, and when members have knowledge that cannot be attributed to the institution. After all,

\footnotetext{
${ }^{6}$ University is a special kind of institution when it comes to knowledge, as knowledge is at the core of its existence. Universities create new knowledge and teach students this knowledge: their activities are all about knowledge.

${ }^{7}$ There may be cases where they should arguably share the information even in the event of ongoing knowledge suppression, but I will not go into these whistleblower cases here.
} 
institutional knowledge is not as simple a matter as a certain percentage of members knowing something. Instead, in order to count as institutional knowledge, the knowledge must be attached to the relevant roles and communication lines. Therefore, in an institution with 500 members, the institution does not know $X$ even if 300 of its members know $X$ as individuals, that is, without having an awareness of each other's knowledge or sharing their knowledge with the executive members. However, the same institution can be said to have knowledge of $Y$ even with only one member knowing $Y$, as long as it is known to the executives (or the relevant manager in the communication line) that the member has this knowledge. An example of the latter could be a lone researcher within a university biology department focusing on some obscure species of frog. No-one else in the university knows anything about these frogs, but as long as the expertise is known to the relevant people along the lines of communication, then this knowledge is available within the institution. Often, institutional knowledge is distributed knowledge, meaning that the individuals who possess the institutional knowledge do not have to be gathered together into a task force or a panel of specialists; rather, they do what they do and the institution has the knowledge because of this. The frog specialist is just such an example.

It should also be noted that institutional knowledge may be more than the sum of its individual parts. Imagine a group of people with varying fields of expertise, and/or epistemic access, thinking together a solution to a problem facing the institution. Together, they can come up with an answer for the institution that is novel and innovative, exceeding the aggregate knowledge of the individual members.

Much institutional knowledge is of course documented in different texts or encompassed in files, software programs and so on. This knowledge can be part of institutional knowledge as long as it is accessible to the executives, senior managers or the people working in areas that need it. (If the files are buried in a basement somewhere, they are lost institutional knowledge). Hence, not all of the building blocks of institutional knowledge are traceable back to the knowledge that the individual members currently have.

The fragmentation of knowledge and information can go too far, however, and this is when the institution is no longer able to make the best decisions as a collective. In these cases, there is either a systematic fault in the lines of communication, or knowledge is suppressed, whether through denials, taboos or secrecy. ${ }^{8}$ Still, for an institution to have knowledge about something, it holds that this knowledge does not have to be shared among all, or even most, of its members. For example, when a

\footnotetext{
${ }^{8}$ Hormio 2018.
} 
group of experts is tasked with finding out about the state of climate change science, and duly reports back to the executives of an institution (or the management level deemed appropriate by the top-level management), the institution has knowledge about the issue. This is so even if the institution in question decides to hide the findings from its regular members or just decides not to take any further action on the matter.

\section{Robustness of institutional knowledge}

While it can be said that the USA has known about climate change for many decades, it is clear that not everyone in the Federal Government, let alone the citizens or denizens of the USA, knew about the issue in the 1970s or 1980s. These days general knowledge about climate change is widely shared (although expertise about the science is not). Looking at how knowledge about climate change has evolved over the years, there seems to be different degrees of institutional knowledge at play. In this section, I will distinguish between two types of institutional knowledge, which I term operating knowledge and shared knowledge.

Let us start with an example of operating knowledge in a group setting. Imagine a spy ring, where the spies do not know the identity of the other spies or have access to the information the others have. ${ }^{9}$ Each spy has been assigned a code name and a secret phone with which to get in touch with the others. They have an assignment to complete where Aja knows the target, Katya the method, and Shea the time and the place. The person who set up the mission was involved in a car crash and is lying in a coma in hospital somewhere. Shea has been instructed to invite the other two to come to the designated place at the designated time, Katya to bring the means, and Aja to put them to use against the target. Between them, they have all the information necessary to successfully complete the assignment. However, can the spy ring as a collective be said to have knowledge about what the assignment is before it is carried out?

I believe that the spy ring does have operating knowledge about the assignment precisely because it is able to carry it out. If the spy ring is part of some organised espionage group, it is the institution rather than the spy ring per se that knows what the assignment is. However, if the person who is now in a coma is some rogue agent, then the spy ring per se has the knowledge. That said, this knowledge is highly fragmented and not robust at all: if one link was missing, they would not be able to achieve their goal. Recall the lone researcher in the earlier example. The knowledge that the university has on these

\footnotetext{
${ }^{9}$ I use the same example in Hormio 2018.
} 
obscure frogs is highly fragmented and dependent on one person (at least until the researcher writes their knowledge down in a research paper, or teaches students a course on the frogs, and so on). Coming back to the spies, the spy ring knows how to perform the assignment, but not that the assignment is to $X$, i.e. what it entails. After they have carried it out, the spy ring will ostensibly also know more about the assignment - who the target was, where, and by what means it was achieved - as the knowledge of the individual group members will have merged through action. Knowing both how to do something and the details of what you are doing constitutes more robust knowledge than knowing just the former.

I refer to knowing how to do something as operating knowledge, and the knowledge that allows the individual members to pool what they know and reflect upon it as shared knowledge. The people directing the institution have to decide what type of knowledge can be fragmented or compartmentalised operating knowledge, and what type of knowledge needs to be shared knowledge, that is, more robust knowledge within the institution. With knowledge about obscure frogs, for instance, it seems acceptable that the institutional knowledge is not robust, and that operating knowledge is sufficient and economical. Sometimes institutional knowledge should also be fragmented, for example when there are concerns about privacy. With other types of knowledge, it might be the case that steps need to be taken to make the institutional knowledge more robust, so that it is widely shared among members.

For operating knowledge to be ascribed to an institution, it must fall in line with the institution's structure regarding institutional roles and lines of communication. Institutional statements, such as principles, codes of conduct or mission statements will help to distinguish rogue behaviour from institutional behaviour within roles. Below, I will provide an example that illustrates these differences in a group setting before applying it to the institutional setting.

A small mobile phone repair company is operated and owned by the five engineers who fix the phones. One of the engineers installs malware in some of the phones. The installation is intentional and all five engineers know about it, although it has never been discussed by them as a group. The engineers as a group have knowledge about the malware. Even without an explicit plan to install the malware, the company can also be said to know about it in the shared knowledge sense, as the five engineers are the only owners and employees of the company. If the company was owned and operated by a sixth person, who did not know about the malware, then the information within the company would be fragmented (on purpose in this case), and the knowledge that the experts had would not be available to the rest of the company. Note that in this case the repair company does not have operating knowledge 
about the malware, even though the company's engineers knew, because the information was not shared along the company lines.

The same would apply if the five engineers were part of a large institution and did not inform others along the lines of communication about what they knew. The experts within the institution knew, so there was fragmented knowledge within the institution about the malware, but the institution did not have operating knowledge in the relevant sense. They could not have warned their customers about the malware, for example, as the institution did not know it was being installed. One could argue that the institution should seek to establish policies and procedures to try to prevent blockages of this sort along its knowledge lines from happening again. This leads us to the parameters of institutional knowledge: what should institutions know? This is the question that I will address next.

\section{Parameters of institutional knowledge}

Institutions have fewer excuses for ignorance than individuals do. Simply hiding behind ignorance rarely works for institutions, as their collective capacity to process information far exceeds any individual's capacities. Institutions can rarely say that they did not know and be done with it. Often, they did have knowledge in the relevant sense, or at least they should have. They can pool knowledge and skills, fund research or have a group of experts dedicate their working hours to thinking through an issue from the institution's point of view. If the required expertise cannot be found among their existing members, they can hire new staff or employ consultants. They can and should do this when new issues arise that affect their operating environment and future operations. As Steve Vanderheiden puts it:

While cognitive limits on the ability to know must allow for some excusable ignorance in the case of persons, states and other large-scale organizations have a much greater ability to process information than do individual persons, and are as a result more circumscribed in their claims to excusable ignorance. ${ }^{10}$

For an institution to be in a position to know $X$, it has to bring enough people together to find out about $X$, to have knowledge that was previously outside the institution. Knowledge flows can of course be interrupted in many ways within institutions, but these are cases where the institution should amend its practices for the better. The institution can draw resources together to find that $X$ when it comes to

\footnotetext{
10 Vanderheiden 2016: 306.
} 
information that is already within the institution, but too fragmented to count as institutional knowledge. In other words, there is a dysfunction of some kind in pooling these resources, and the institution wants to address this.

In general, it is the responsibility of the institution to make sure that when it comes to important issues, the information that it has is not too fragmented across departments, and that members are aware of the issue at least to the degree relevant for their roles. In other words, the institution has to carefully determine which knowledge should be shared within the institution.

In theory, the parameters of institutional knowledge are set by the executive levels of the institution, laying out what knowledge the institution should have or obtain in the future, and in which areas it can remain ignorant. In practice, the picture is not this simple, however. Much institutional knowledge is acquired without top-down directives and incentives, based purely on the interests and dislikes of its members. The frog researcher is a case in point. Institutions can also have information that leads to only partial knowledge, or the information it has is misleading. The more complex an institution is, the more it is prone to errors. There might even be a system failure due to a design fault in the institution, resulting in ignorance. Systemic errors should be addressed at the earliest opportunity once they become apparent. They should be actively looked for and tested for at least in core areas of the institution, although there will always be surprises.

Along with errors and systematic failures, a major challenge for institutional knowledge is so-called tacit knowledge. This kind of institutional memory is difficult, almost impossible, to document in writing and in guidelines. Rather, it gets passed on from one employee to another and is retained in the memory of long-serving members of staff. Retaining this institutional memory is a major practical challenge for all institutions, and it also raises interesting questions about who needs and should have knowledge in times of large-scale restructuring and institutional change.

Lack of institutional knowledge can also be rooted in ignorance about knowledge and facts. What I call knowable recognised unknowns are issues that could be addressed, given the right resources and motivation. ${ }^{11}$ There is no science or technology lacking when it comes to obtaining knowledge about these facts, rather they are either outside the focus of the institution, or the benefits derived do not warrant the expenditure in terms of resources. If something is clearly outside the focus of the institution, leading to a lack of motivation in acquiring the knowledge in question, the resulting

\footnotetext{
11 Hormio 2018.
} 
ignorance is justified. A library does not have to know about the intricacies of mortgage lending, but a bank involved in such lending should. ${ }^{2}$

I would argue that institutions with the capacity to process a lot of information have greater obligations to know about complicated large-scale social issues than individuals, as long as the issue falls within their scope of interest. After all, institutions have fewer excuses for being ignorant about facts than individuals do, as argued above. Some institutions should also know how certain issues affect their members. For example, states should know how climate change is likely to affect their citizens, as protecting their interests is one of the reasons for the continued existence of states as institutions.

What an institution should know depends on its focus, its ethos, namely the reason(s) for the continued existence of the institution. Ethos consists of the central questions and practical matters that are vital to the purpose of the group (the group's realm of concern) and the answers it has collectively accepted as its view (intentional horizon). ${ }^{13}$ The ethos thus covers the central goals and commitments of an institution. However, it is not set in stone, as elements may change (and almost always do, even in very conservative institutions). The institutional ethos is thus in a state of flux to a degree. Examples abound: political parties amalgamate new goals, the jurisdiction of local authorities changes, a university begins to offer courses in a new subject, financial institutions come up with a new product, and so on.

To simply state that some knowledge is currently outside the realm of concern of an institution does not, in itself, settle much in terms of the normative question pertaining to the responsibility of institutions. As institutions are responsive to their environments and must regularly review their realm of concerns as well their intentional horizons, knowable recognised unknowns are always a normative matter. This applies to universities and corporations, libraries and banks alike. To give just one example, the intentional horizon of a state government often changes after an election, resulting in new answers to central questions vital to the institution. This is reflected as changes in policy: the new answers can and often do conflict with the previous answers (e.g. tax rates go up or down, money is allocated differently).

When the intentional horizon of an institution changes, from the viewpoint of institutional knowledge there should still be consistency despite the changes. I do not refer to policy changes here, as there is

\footnotetext{
${ }^{12}$ Fragmentation of knowledge could also be described in terms of knowable recognised unknowns, as the process of specialization and coordination allows them to be confined to or sustained within parts of the institution. With institutional operating knowledge, the fact that some members of the institution have the knowledge is often widely known, so for the other members expert knowledge on a given issue is a knowable recognised unknown at the individual level.

${ }^{13}$ Laitinen 2014; Tuomela 2007.
} 
no inconsistency from the viewpoint of institutional knowledge (although a state's policies could be inconsistent in other ways). Policy changes are a normal feature of institutional politics. Rather, what I have in mind is consistency in knowledge claims. For example, can the U.S. federal government really claim at this point in time that climate change is not a priority and cast doubt on science previously endorsed by their own agencies? Of course they can - and do - but the claim is inconsistent with the knowledge that the government has previously admitted to be privy to. I will discuss this in the next section, where I return to my case study concerning institutional knowledge of climate change.

\section{Climate change knowledge revisited}

Climate change offers fertile ground for discussing institutional knowledge claims. It is a common misconception that climate science, or even climate policy, is something new. In 1895, Svante Arrhenius presented a paper to the Stockholm Physical Society on the influence of carbon in the atmosphere on the surface temperature of the Earth. ${ }^{14}$ Charles David Keeling, a researcher at the Scripps Institution of Oceanography, began measuring carbon dioxide concentration in the atmosphere in 1958. His research showed that the concentration was rising steadily roughly relative to the amount of fossil fuel burned. The data gathered would later become known as the Keeling Curve. The measurement has been taken at the Mauna Loa Observatory in Hawaii ever since, providing the longest continuous data on $\mathrm{CO}_{2}$ concentration. ${ }^{15}$

Scientists were quick to alert the policymakers and the U.S. Federal Government has known about climate change for many decades as an institution. Knowledge about climate change can thus be attributed to the USA as a nation state in the operative knowledge sense (the knowledge of U.S. citizens and denizens is a different question). President Lyndon Johnson mentioned the effect that carbon dioxide and fossil fuels have had on the global atmosphere in a speech to the United States Congress as early as 1965 . As global warming began to gain wider scientific interest and was noticed at the top levels of the administration in the U.S. during the latter half of the 1970s, it prompted an increasingly organised and determined response from groups and individuals with either vested interests in the fossil fuel industry, or ideological distaste for any environmental concerns that could bring with them added regulation and government involvement in the market. ${ }^{16}$

\footnotetext{
${ }^{14}$ Fleming 1998.

15 Monroe 2013.

16 Oreskes and Conway, 2010: 170-71.
} 
I have argued that what matters for institutional operating knowledge is whether the relevant people knew, usually the experts and the executives. Apart from cases like Juliana et al., which are directed towards governments, there are currently several legal cases underway in the USA and elsewhere concerning the knowledge that certain oil companies had about climate change back in the early 1980s. One question concerns whether or not these institutions misled their shareholders by not making their operating knowledge available to them, namely by making it shared knowledge among the stakeholders of the institution.

For example, there is a discrepancy between the way in which ExxonMobil saw climate change internally, and the message it communicated externally through paid advertisements and other PR efforts. ${ }^{17}$ Internal documents show that ExxonMobil's scientists and managers were able to identify climate change as a potential threat to its business interests even by the early 1980s. They also acknowledged its anthropogenic nature (i.e. that it is caused by humans). These documents "consistently tracked evolving climate science" and acknowledged that climate change "is real, humancased, serious, and solvable". ${ }^{18}$ However, the corporation's message in its advertorials was different and concentrated on emphasising the uncertainties in the science. Their external communications thus promoted a narrative that was inconsistent with the operating knowledge that the institution held about the science.

Although Exxon has possibly been the most persistent lobbyist, it was not the only corporation to adopt a public stance on climate change that contrasted with their internal documents on the issue. Another example is Royal Dutch Shell, which understood the gravity of climate change as early as the 1980s, some ten or twenty years before the severity of the threat entered the public consciousness. This operating knowledge is demonstrated in the quote below from their confidential 1988 report The Greenhouse Effect.

It is estimated that any climatic change relatable to $\mathrm{CO}_{2}$ would not be detectable before the end of the century. With the very long time scales involved, it would be tempting for society to wait until then before doing anything. The potential implications for the world are, however, so large that policy options need to be considered much earlier. And the energy industry needs to consider how it should play its part. ${ }^{19}$

\footnotetext{
17 Supran and Oreskes 2017.

18 Supran and Oreskes 2017: 15.

${ }_{19}$ The confidential report The Greenhouse Effect has been deposited in Climate files, and is available at www.climatefiles.com/shell/1988-shell-report-greenhouse.
} 
Shell had set up a Greenhouse Effect Working Group, who warned in that same confidential report that by the time the effects were detectable around the turn of the century, namely around the present time, it might already "be too late to take effective countermeasures to reduce the effects or even stabilise the situation". However, despite this operating knowledge, Shell lobbied against regulation and effective measures to tackle the problem early on through the Global Climate Coalition (GCC), which was formed in 1989 to act as a counterforce to the Intergovernmental Panel on Climate Change (IPCC). The GCC counted among its members big oil companies, car manufacturers, and industry associations, spreading misleading information to discredit climate science and foster scepticism about it in order to keep legislation at bay to protect profits in the short-term. It seems that Shell had a strong operating knowledge about climate change science, but this knowledge was not shared knowledge among its shareholders, let alone among other stakeholders. Its own experts had recommended that the industry should consider how to play its part in finding a solution to the emerging problem, but maybe this knowledge was too painful for the industry to properly process at the time. Be that as it may, the end result was a cynical delaying of action and buying more time.

I argued at the end of the last section that even with changes to its intentional horizon, an institution should not be making inconsistent knowledge claims. What I have in mind are claims such as climate change not being the top environmental priority, made by the new head of the U.S. Environmental Protection Agency (EPA) in 2019.20 Even with a new intentional horizon, such claims are inconsistent with the knowledge that the institution has.

While such a statement is clearly a statement by an official appointed to represent the institution, and therefore a claim made by the EPA, it is also an inconsistent statement in the light of previous statements and reports by the institution. As the science that the previous position was based on has not changed (i.e. no new scientific evidence has emerged that would make climate change less of a threat), this means either that the claim is in contrast to what the institution in fact knows, or that the institution is no longer able to draw together the necessary resources to have knowledge on the issue.

In either case, it could prove embarrassing to the institution if the plaintiffs in Juliana et al. were allowed discovery, that is to obtain evidence from the other party. It could be that they would obtain evidence showing that what EPA scientists and other experts within the institution know about climate change is indeed inconsistent with what the EPA now states publicly. It is possible that the public

\footnotetext{
${ }^{20}$ Hook and Stacey 2019.
} 
statements by the institution are inconsistent with its operating knowledge, which seems to have been the case with the oil companies. It is even possible that the statements are inconsistent with the shared knowledge of the institution.

The case shows how institutional knowledge can be awkward to deal with when there is a change in the administration of an institution. When the current U.S. government took charge, it purged a great deal of information from government websites. To give an example, the section on the EPA website that used to be dedicated to climate change (www.epa.gov/climatechange) can now only be found in the archived version and is no longer updated. ${ }^{21}$ Some material on climate change disappeared altogether and words have been adjusted throughout the website. ${ }^{22}$ While climate change was listed as one of the popular topics on the frontpage of the EPA website in January 2017, the frontpage no longer even includes climate change in its list of "Key Topics", focusing instead on other issues such as mould. ${ }^{23}$ In addition, the EPA set new rules to prevent certain data from entering its regulatory decision processes, and also to get rid of some of its experts, as leading scientists who have received EPA research grants were replaced by industry-funded scientists. ${ }^{24}$ This effectively changes who is allowed an expert status and say within the institution. Actions like these could be construed as waging war on the EPA's institutional knowledge.

\section{Closing remarks}

Although attributions of institutional knowledge are for the most part context-specific, we can still say that institutions have knowledge about something when the members tasked with dealing with knowledge in this area possess it, and the knowledge is attached to the appropriate lines of communication. This knowledge comes in degrees, depending not only on how well the lines of communication work and how fragmented the information is, but also on what the knowledge is used for. Sometimes operative knowledge is preferable to shared knowledge. What is clear is that ignorance on its own rarely excuses institutions..$^{25}$

\footnotetext{
21 The archived January 2017 website can be found at https:/ / 19january2017snapshot.epa.gov.

22 Barron 2018.

23 The EPA website (www.epa.gov) was accessed on 30 September 2019.

24 Cornwall 2017.

${ }^{25}$ I would like to thank the participants at the Glasgow workshop for their comments and feedback, especially Jessica Brown and Kirk Ludwig, who pressed me on key points. Special thanks are due to Miguel and Rachael for putting together such an engaging workshop and following it up with this book.
} 


\section{Bibliography}

Barron, Laignee (2018) “Here's What the EPA's Website Looks Like After a Year of Climate Change Censorship". Time.com, 1 March 2018, available at https://time.com/5075265/epa-website-climatechange-censorship.

Blumm, Michael C. and Mary C. Wood (2017) “No Ordinary Lawsuit”: Climate Change, Due Process, and the Public Trust Doctrine". American University Law Review 67(1), 1-87.

Cornwall, Warren (2017) “Trump's EPA has blocked agency grantees from serving on science advisory panels. Here is what it means". ScienceMag.org, 31 October 2017, available at https://www.sciencemag.org/news/2017/10/trump-s-epa-has-blocked-agency-grantees-servingscience-advisory-panels-here-what-it.

Fleming, James Rodger (1998) Historical Perspectives on Climate Change. Oxford: Oxford University Press.

Hook, Leslie and Kiran Stacey (2019) "Climate change not top environment priority, says new EPA chief”. Financial Times, 30 April 2019.

Hormio, Säde (2018) "Culpable ignorance in a collective setting”, in Jaakko Kuorikoski and Teemu Toppinen (eds.) Action, Value and Metaphysics - Acta Philosophica Fennica 94 (XCIV), 7-34.

Juliana v. U.S. (2015) First Amended Complaint for Declaratory and Injunctive Relief 6:15-cv-01517-TC.

Juliana v. U.S. (2017) Federal Defendants' Answer to First Amended Complaint for Declaratory and Injunctive Relief 6:15-cv-01517-TC.

Laitinen, Arto (2014) "Collective Intentionality and Recognition from Others", in Anita Konzelmann Ziv and Hans Bernhard Schmid (eds.) Institutions, Emotions, and Group Agents: Contributions to Social Ontology. Dordrecht: Springer Science+Business Media, 213-227.

Monroe, Rob (2013) "The History of the Keeling Curve", Scripps Institution of Oceanography, 3 April 2013), available at https://scripps.ucsd.edu/programs/keelingcurve/2013/04/03/the-history-ofthe-keeling-curve.

Oreskes, Naomi and Erik M. Conway (2010) Merchants of Doubt: How a Handful of Scientists Obscured the Truth on Issues from Tobacco Smoke to Global Warming. New York: Bloomsbury Press.

Rubinton, David S. (2017) "Save Yourselves, Kids: The Atmospheric Trust Litigation". Natural Resources \& Environment, 32(2): 11-14.

Supran, Geoffrey and Naomi Oreskes (2017) Assessing ExxonMobil's climate change communications (1977-2014). Environmental Research Letters 12.

Tuomela, Raimo (2007) The Philosophy of Sociality: The Shared Point of View. New York: Oxford University Press.

Vanderheiden, Steve (2016) "The Obligation to Know: Information and the Burdens of Citizenship". Ethical Theory and Moral Practice 19(2): 297-311.

Wood, Mary Christina (2013) Nature's Trust: Environmental Law for a New Ecological Age. New York: Cambridge University Press. 